\title{
PROJECT MUSE'
}

Norms of Epistemic Diversity

Miriam Solomon

Episteme: A Journal of Social Epistemology, Volume 3, Issue 1-2, 2006, pp. 23-36 (Article)

Published by Edinburgh University Press

DOI: https://doi.org/10.1353/epi.0.0007

$\Rightarrow$ For additional information about this article https://muse.jhu.edu/article/209438 


\title{
Miriam SOLOMON
}

\section{Norms of Epistemic Diversity}

\begin{abstract}
Epistemic diversity is widely approved of by social epistemologists. This paper asks, more specifically, how much epistemic diversity, and what kinds of epistemic diversity are normatively appropriate? Both laissez-faire and highly directive approaches to epistemic diversity are rejected in favor of the claim that diversity is a blunt epistemic tool. There are typically a number of different options for adequate diversification. The paper focuses on scientific domains, with particular attention to recent theories of smell.
\end{abstract}

Epistemic diversity is widely approved of by social epistemologists. Epistemic diversity often produces dissent on the theories or the strategies worth pursuing. Dissent is valued for at least three reasons: it produces worthwhile criticism (e.g. Mill, Feyerabend, Popper, Longino), division of cognitive labor (e.g. Hull, Goldman, Kitcher, Solomon) and social distribution of knowledge (e.g. Haraway, Longino, Solomon, Sunstein).

Another epistemic value of diversity is creativity. Intellectual biographies often point out aspects of an investigator's background that made them different from others thinking about the subject and led to their unique contribution to a field. For example, Wegener's experience with icebergs in Arctic exploration and his knowledge of meteorology were cognitive resources for his later idea that continents can drift. Creativity is not discussed much by mainstream social epistemologists. The traditional focus is on reasons and causes of choice among available alternative theories, rather than on the creation of those alternatives themselves. Perhaps this is due to a traditional focus on the context of justification rather than the context of discovery. Creativity is discussed more-at least implicitly—by feminist social epistemologists. For example, Helen Longino sees her interactive model of the causes of human behavior as developing from feminist values. This paper will, likewise, consider the context of discovery as well as the context of justification.

The main question to be discussed in this paper is How much epistemic diversity and what kinds of epistemic diversity are normatively appropriate? Should we be doing anything to increase or decrease the amount of diversity or the types of diversity? I'm going to focus on scientific domains, because that is my area of expertise. There may be implications for other knowledge domains.

Two positions on epistemic diversity are already well known. First, the laissez-faire view that there is enough epistemic diversity, and no special efforts need be made to increase 
(or decrease) the amount of diversity. ${ }^{\mathrm{I}}$ Second, there are normative recommendations by feminist philosophers of science (for example Evelyn Fox Keller and Helen Longino) to increase epistemic diversity in specific ways, for example by increasing the number of scientists who work with interactive rather than linear hierarchical theories. I will show, in the context of a case study on recent theories of smell, that neither of these positions is quite correct. Rather, I shall argue that appropriate norms for epistemic diversity typically suggest a number of different options for adequate diversification. I will conclude that diversity is a blunt epistemic instrument. (In contrast, it often needs to be a highly specific political instrument.)

\section{EXAMPLES OF EPISTEMIC DIVERSITY AND DISSENT}

Here is a classic example of the epistemic success of epistemic diversity. (I take this from Surowiecki 2004). Francis Galton, who was Darwin's half-cousin and the founder of eugenics, discovered in 1906 that ordinary people-a group of approximately 800 people visiting a fair in Plymouth-made an excellent estimation of the weight of a fat ox. In fact, the mean of the estimates was I,197 pounds and the actual weight was I,I98 pounds. Individuals who had some expertise in the weight of oxen (farmers, butchers) did not individually do as well. This result is readily replicated for similar tasks, such as estimating the number of jelly beans in a jar.

Why do these aggregated decisions do so well? The typical explanation (also given in Surowiecki 2004) is that, when aggregated, "biases cancel out" so that the result is more accurate. But individual biases could "cancel out" and the result still be wildly off. For example, the aggregated USA population opinion about the likelihood of weapons of mass destruction in Iraq in 2003 was far from the truth. Systematic biases-such as trust in authority, in this case-can skew the aggregate result of a whole community. Thus, we also need to understand what it is that individuals are doing that is right in some way. Are individuals all working out the weight of the ox using the same basic algorithm and then skewing their answers by their particular biases? Hardly likely. Biases don't work that way. (If they did, perhaps we could get rid of our biases and have "pure thought"!) More likely, individuals are using a variety of algorithms or heuristics, each of which has a particular way of calculating the result, and each of which has some merit, some ability to capture the truth of the situation, and each of which has some demerit (or "bias").

From an epistemic point of view, it is better to have 800 ordinary opinions on the weight of the ox than it would be to have one expert's opinion, or the most popular ordinary opinion, or even some opinion obtained by trying to get 800 people to debate to consensus (such debates are highly vulnerable to "groupthink" and other biasing phenomena). 800 opinions contain more information, and yield a more accurate result, than do expert individuals or consensus processes (of course, provided one knows how to extract that information). In this case, the information is obtained simply by taking the arithmetic mean; other cases are more complex.

Cass Sunstein's recent book, Why Societies Need Dissent (2003), is full of examples of situations in which coming to consensus led to poor epistemic results, precisely because it resulted in the loss of important information. ${ }^{2}$ For example, Sunstein understands 
the Bay of Pigs fiasco, in which President Kennedy and his advisors reached consensus on taking aggressive military action, as the outcome of repressing dissenting voices that came from people who had important information relevant to the decision. If those dissenting voices (e.g. of Arthur Schlesinger, Jr.) had been heard, the information would have been shared, and that particular consensus avoided. In order to be epistemically valuable, dissenting voices do not need to be correct overall: they just need to come with important information.

\section{ARE NORMS OF DIVERSITY NEEDED?}

If diversity is good, how much diversity is best? Are any particular causes of disagreement more epistemically beneficial than others? The laissez-faire (sometimes also called invisible hand) position says that there is typically, or always, an adequate amount of epistemic diversity. The causes of disagreement somehow always manage to bring about exactly, or approximately enough, the right amount and kind of epistemic diversity. For example, Frederick Grinnell (1992) suggests that the usual composition of a research group - a mixture of senior, junior and novice scientists—provides the right amount and kinds of intellectual diversity. Senior scientists provide necessary resistance to new ideas and junior scientists and novices provide flexibility and creativity. Similarly, Philip Kitcher (1993) argues that cognitive labor can be adequately distributed by factors such as the desire for credit. A scientist may choose to work on a theory not because she judges it the most plausible but because she judges that her personal chance of credit is highest with this theory. This is the case when, for example, many scientists are already working on the most plausible theory. Kitcher constructs models of ideal epistemic choice and compares the results with those of models of epistemic choice that allow the desire for credit to influence choice. The results are close.

In the case of Grinnell and Kitcher (and probably Feyerabend), the laissez-faire view comes from epistemic reflection. In some cases, however, laissez-faire positions are politically motivated. For example, Michael Polanyi (1962) argued for a laissez-faire attitude towards dissent, fearing that any attempt to control scientists interferes with the openness of inquiry.

Feminist philosophers of science have been clear that they do not think that there is enough dissent or enough epistemic diversity. They write in a normative voice, recommending increases of particular kinds of epistemic diversity in science. They are definitely NOT laissez-faire. For example, Evelyn Fox Keller (1985) and Helen Longino (1990) both argue for an increase in the number of scientists who prefer to model the world with complex interactive theories. They base their arguments on examination of several case studies: twentieth century genetics, theories of the life cycle of slime mould and interpretations of quantum mechanics (Keller) and biological models of the causes of human behavior (Longino). They claim that too many scientists preferentially model the world with simple linear theories. And they both associate simple linear thinking with traditional masculinist hierarchical thinking, and complex interactive theories with more enlightened feminist thinking. Their arguments for improving scientific practice are motivated by political as well as epistemic goals: they want feminist theorizing to 
become more widespread both because it will come with emancipation for women (and men) and because it is good for science.

I agree with feminist philosophers of science that there is not enough epistemic diversity among scientists. I take the question about cognitive diversity further, asking not only questions about specific styles such as linear hierarchical versus complex interactionist theorizing. I ask about the contribution of any kind of diversity to any particular scientific question. It might seem that some kinds of diversity are not relevant for some scientific questions. For example, Cass Sunstein doubts that racial diversity contributes to success in physics and mathematics (2003, p. 206). And many have doubted the relevance of gender diversity for sciences in which the word "gender" or "sex" does not appear, such as chemistry, geology, physics and engineering. The work of Evelyn Fox Keller, Karen Barad and others challenge these claims about irrelevance of diversity: they have shown that ideologies about gender have been expressed in a wide range of theories in physical as well as biological science. And insofar as ideologies about gender overlap with ideologies of race (both, for example, presuppose simple linear hierarchies), we can expect that ideologies about race are also expressed in a wide range of theories.

I have found it impossible to show of any kind of cognitive diversity that it is irrelevant to a particular open (i.e. unresolved) scientific question. I have tried to come up with examples and failed. But I have noticed that while all kinds of diversity can be useful, sometimes more than one source of diversity can serve the same function. For example, science generally benefits when some scientists pick new and risky theories to work on. Many psychological and social factors can lead to choice of a new and risky theory over an old and established theory, such as personality (risk takers in general are more likely to pick riskier theories in particular), age (younger scientists pick riskier theories than do older scientists), competitiveness and the desire for credit (which lead to some scientists picking a new theory because older theories already have adherents-see Goldman and Shaked 1992 and Kitcher 1993). In principle, any one of these could suffice as a source of diversity for producing the required distribution of cognitive effort. In practice, one or more may do the work of distributing cognitive effort.

While all kinds of diversity are potentially relevant to a scientific question, and sometimes more than one kind of diversity can serve the same function, there may be some instances in which a particular kind of cognitive diversity is indispensable. For example, feminist perspectives may be indispensable to research on divorce and intersex perspectives indispensable to research on "corrective" sex surgery. I expect, however, that such cases are restricted to those in which the scientific domains themselves concern particular kinds of human diversity.

For the most part, diversity is a blunt epistemic tool. ${ }^{3}$ What I mean by this is that more than one type of diversity can usually do any particular job of diversifying. What does this mean for normative recommendations? Insofar as we are able in advance to identify the kind of distribution of research effort (or knowledge) that is needed and missing, there will be more than one kind of normative recommendation, each achieving the same (or similar) outcome.

These general reflections can be made more precise, and applied to particular cases. What I'm going to do here is use a framework I developed a few years ago to discuss 
some normative features of dissent, and present a new example that will illustrate the framework and, I hope, take it further.

In Social Empiricism (200I) I developed a normative account of division of cognitive labor and knowledge in science. To summarize, I conceptualize cognitive diversity in terms of decision vectors influencing the thinking of individuals and communities. Decision vectors are motivational, social, cognitive, ideological, etc. factors that influence the outcome (direction) of a decision. I distinguish between empirical and non-empirical decision vectors. Empirical decision vectors are causes of preference for theories with empirical success (either empirical success in general or one empirical success in particular), e.g. preference for theories with novel empirical success, or a preference for a theory with a particularly salient empirical success. ${ }^{4}$ Non-empirical decision vectors are other reasons or causes for choice, e.g. preference for theories with hierarchical ideology, preference for simpler theories, holding onto a theory because of pride. Decision vectors are individuated by the theories of choice in which they occur, and identified by case studies using whatever historical resources and techniques are available. Social Empiricism argues that three conditions are necessary for a normatively appropriate dissents:

I. Theories on which there is dissent should each have associated empirical success.

2. Empirical decision vectors should be equitably distributed, i.e. in proportion to empirical success.

3. Non-empirical decision vectors should be equally distributed, i.e. the same number for each theory.

The argument depends on examination of case studies, which show that satisfaction of the three conditions is linked to scientific success (scientific success is understood in terms of empirical success and/or truth). The condition of particular interest here is number 3. Conditions I and 2 are more easily satisfied, and certainly satisfied in the example that follows. Note that Social Empiricism requires the same number of non-empirical decision vectors for each theory, but it does not specify the particular kind of decision vectors or the magnitude of decision vectors. All that is specified is the "direction" of the decision vector, i.e. which theory it is skewed towards. It is an "improper linear" normative model, a first estimate of what, ideally, would be a more fine-grained normative recommendation.

\section{EXAMPLE}

In this section I will present and analyze a new example. ${ }^{6}$ My goal is to show what normative assessment looks like. The analysis is definitely not laissez-faire: in this example we need more distribution of cognitive labor, especially at the beginning of the story. But the analysis does not make specific recommendations (such as, "hire more Hispanic people in this field"). In particular, the analysis does not call for balancing "interactive" and "linear hierarchical" ideologies, although such ideologies may play a significant role in theories of smell. Social Empiricism gives several choices for intervention to produce better division of cognitive labor. In practice, of course, some interventions may be easier, 
more available, or perhaps more desirable for political reasons than others. This case study is also suitable for looking at norms of diversity for scientific creativity. In this analysis, I go beyond the tools of Social Empiricism.

Chandler Burr's The Emperor of Scent: A Story of Perfume, Obsession and the Last Mystery of the Senses (2002) ${ }^{7}$ is a story of a novel scientific theory and its rejection (so far) by both the science and the technology communities. At the same time, it is the story of a maverick theorist, a larger than life personality-Luca Turin-who proposes this theory. And it is a story: written by a journalist, Chandler Burr, who is clearly a convert to Turin's way of thinking. The whole story-this book put together with Luca Turin's just-published book The Secret of Scent (2006) and the published scientific studies supporting and challenging Turin's theory-is, right now, complex and unfinished. It is an excellent example of a scientific controversy under way: the sort of case that Harry Collins relishes, with disputes about the interpretation of data, challenges to authority and lively dynamics of personality. Chandler Burr's book has received a good deal of mostly positive popular attention, perhaps because stories of maverick individual scientists (the eventually successful ones, at least!) are so celebrated in our culture.

The generally accepted theory of scent is that particular scents are detected by shape receptors in the nose, which detect the shape of the molecules (or parts of molecules) that make up those scents. Several hundred different kinds of scent receptors recognize different molecular shapes. A particular smell may be due to stimulation of a specific receptor or, more likely-since there are more smells than there are receptor typesstimulation of a particular range of receptors, whose signals are then processed by the brain. This theory was proposed by Linus Pauling in 1946 and developed by R.W. Moncrieff, John Amoore and others and has been accepted by both scientists and the perfume industry since the rig7os.

Luca Turin observed that the shape theory has never been developed enough to make predictions about what a molecule will smell like, based on its shape. Nor has data mining the huge inventories of perfume companies discovered robust shape-smell correlations. In fact, molecules that are similar in shape sometimes smell very different. Turin's best example of this is that isotopes of the same substance, which are almost the same shape, often smell quite different. For example, Turin obtained the Hydrogen and Deuterium versions of acetophenone. The $\mathrm{H}$ version "had a slightly gluey smell, like artists' rubber gum, a toluene smell" (p. 179). The D version smelled "fruity instead of toluene, lighter. Different." (p. 179). Moreover, molecules that are very different in shape sometimes smell almost the same. For example, four different molecules, each very differently shaped, smell of ambergris (which is actually the undigested and rancid vomit of whales). And boranes, which contain no sulphur and have a very different shape from sulphurs, smell sulphurous. Tellingly, borane-hydrogen bonds have almost the same vibrational frequency (2550) as sulphur-hydrogen bonds (2500). Turin's own theory about the detection of smell, a development of the frequency theory of Dyson (1938) and Wright (1977), is that smell detectors work by probing the vibrational frequencies of odorant molecules. The probing is done with inelastic electron tunneling, a quantum mechanical phenomenon. Turin's theory predicts that molecules with the same vibrational frequencies will smell the same, and that the closer the vibrational frequencies, the closer the smell. 
Frequency theory was originally discredited by the observation that enantiomersmolecules that are mirror images of one another and therefore have the same vibrational frequencies-sometimes smell different. For example, R (right-handed) carvone smells of mint but $S$ (left-handed) carvone smells of caraway. Turin addresses this problem by adding a layer of complexity to his theory. Receptor sites need to hold onto the odorant molecule in order to probe its vibrational frequency, and that the hold is accomplished by chemical fit. So Turin adds a shape filter to his overall frequency account. Enantiomers can be detected by different receptor sites. Smell information processing is a matter of combining both the information about the vibrational frequencies and the particular detector. Hence, enantiomers may smell different, but do not always smell different; in fact, most smell the same. ${ }^{8}$

Turin also showed that we can smell parts of molecules that are hidden inside other parts and thus inaccessible to shape recognition. Sterically hindered phenols provide an example of this. In 2, 6 ditertbutyl phenol, the $\mathrm{OH}$ group is hidden inside the molecule. In 2, 4 ditertbutyl phenol it is accessible from the outside. BOTH molecules have the typical $\mathrm{OH}$ "phenolic" odor. Finally (but early in the chronologic story), Luca Turin demonstrated that electron tunneling through proteins is possible by performing an experiment (in 1989) in which he constructed a diode out of egg white. He patented the device.

The story is made more colorful by description of Turin's great "nose." Turin has an ability both to discriminate smells and to vividly describe them. Turin collects great perfumes and wrote a 79-page guide to perfumes (in French, in Paris, in 1994) that created a stir in the professional perfume world as well as the consumer market. Here are some examples of Turin's prose (the French examples are translated by Chandler Burr), both from the perfume guide and elsewhere:

Rive Gauche (Yves Saint Laurent) Thanks to Rive Gauche, mortals can at last know the scent of the goddess Diana's bath soap. A true emblem of the ' 70 , this sumptuous reinterpretation of the innovative metallic note found in the less fortunate Calandre (Paco Rabanne) belongs to the uncrowded category of sculpture perfumes. Its seamless silvery form, initially hidden by white, powdery notes, soon pierces the clouds and gains height by the hour. Like Chamade (Guerlain), Rive Gauche enjoys a peculiar relationship with intensity: the more time passes, the stronger its grace becomes, as if fading allowed its inner light to radiate more easily. A masterpiece. A notable example of the perfect agreement between container and content, its atomizer of metal and blue stripes, at once precious and whimsically "industrial," is itself an item of undying chic. The perfume seems slightly superior in quality to the eau de toilette.

$\mathbf{5 7}$ for Her (Chevignon) Chevignon is a fashion house of such toe-curling vulgarity that one finds oneself hoping that they will never come up with a good fragrance, for one would then have to praise it. Fortunately that possibility remains as remote as ever. 57 for Her is a sad little thing, an incongruous dried-prunes note with a metallic edge that manages the rare feat of being at once cloying and harsh.

Python (Trussardi) The absurdly named Python is a poverty-stricken sweet-powdery affair, a very distant relative of the wonderful Habanita (Molinard). It belongs in a tree shaped diffuser dangling from the rearview mirror of a Moscow taxi. 
Rush (Gucci) The charm of this perfume is entirely man-made, no mention of Nature e.g. flowers etc. This thing smells like a person. To be exact, thanks to the milky lactone note, it smells like an infant's breath mixed with his mother's hairspray ... What Rush can do, as all great art does, is create a yearning, then fill it with false memories of an invented past....

Is the description of Turin's nose relevant to the development of his theory? Chandler Burr does not explicitly address this question, although he implicitly suggests that Turin's nose is central to the story. It's likely that Turin's nose is relevant in generally motivating his interest in theories of scent, in his finding the dominant theory lacking, in helping to supply him with lots of examples to test, in getting him access to the procedures of perfume manufacture, and in giving him the ability and confidence to describe the data. Turin's conviction that smell is objective is additionally relevant. For Turin, the world of scent is as objective and as fascinating as the world of color for interior decorators and the world of sound for music critics. I would suggest that this makes the examples he develops more cognitively salient to him than they might be to others. Certainly he develops an array of empirical decision vectors in support of his theory.

The scientific community has not responded much to Turin's work. The only discussion in the literature that I have been able to find is a recent Nature Neuroscience article (Keller and Vosshall 2004) and an editorial (unsigned), quite harsh in its treatment of Turin's ideas. Perhaps this journal is especially defensive because of the parent journal, Nature's, rejection of Turin's original article. The Keller and Vosshall article, however, contains a three-part test of Turin's theory whose results are worrisome. Instead of using Turin's nose or other expert noses, it uses a panel of naïve subjects. The subjects were unable to tell the difference between acetophenone and deuterated acetophenone, a key observation of difference for Turin. Turin has suggested that the subjects were inadequately trained, and that there may have been problems with the purity of the samples. Despite the Harry Collins-like debate over interpretation of these data, I expect that many of Turin's experimental results will stand, and my analysis depends on this expectation, which is the judgment that Turin's theory has some unique empirical successes. It is notable that Turin does not produce idiosyncratic observations; most of his smell observations are replicated by chemists or fragrance scientists.

What about the non-empirical decision vectors? My analysis of these comes not only from my reading of Chandler's book but also from several book reviews (both published and informal, e.g. on amazon.com) and from the limited response in the scientific literature. Here's a list of the non-empirical decision vectors I have detected:

I. Conservativeness in the academic community. There is a general resistance to changing the theory that has had a monopoly for at least 30 years. Not only is shape the accepted theory for detection of smell, but also many biological receptors (digestive enzymes, neurotransmitters, immune system) work on the basis of shape. People simply did not read Turin's work and did not feel that they had to read it before developing a negative opinion of it; if they did read it, the criticisms were often unfair. Chandler Burr judges this as a "failure of the scientific process" (2002, p. 228). I think it is science as usual, and just needs to be considered in the balancing of non-empirical decision vectors. 
2. Protectiveness of industry. Many people in industry are resistant to a theory that promises to make a great deal of labor redundant, and to make proprietary knowledge more generally available by means of an algorithm.

3. Luca Turin's behavior as a member of the scientific community has often worked against him. Turin is impatient, and doesn't like to play by the rules. When his article was finally turned down by Nature, he sent it to a much more specialized journal on the rebound, Chemical Senses. Turin had met the editor of this journal and received encouragement from him. Turin could have sent the paper to Science or Cell or Proceedings of the National Academy of Sciences or some other prestigious journal. Chemical Senses did not independently peer referee the paper, judging that the Nature reviews were enough, although they did not read them. It then published Turin's paper under the curious heading of "Original Research Paper," signifying nonstandard epistemic status. Turin did not send abstracts or posters to scientific conferences in which he might have presented his theory, although, according to Chandler Burr, he complained that he was not getting enough invitations. Since Turin is an outsider to the academic research community on smell—this was his first paper on the topic-it is especially important to gain trust in the community by respecting their conventions and networking in person.

These first three non-empirical decision vectors work against Turin's theory. They contribute to the sense of both Chandler Burr and the reader of the story that "the deck was stacked against him." This intuitive normative judgment is supported and given shape by Social Empiricism, which says that 3 non-empirical decision vectors on one side and none on the other is not an equal balance of decision vectors.

The next two non-empirical decision vectors, which came later, work for Turin's theory or have the potential to do so. The balance of decision vectors has improved over time, and may improve further.

4. Chandler Burr's biography has drawn a great deal of attention to his theory, much of it sympathetic attention. Chandler Burr presents Luca Turin as a romantic hero, who develops his theory alone and in the face of much resistance.

5. In 200r Luca Turin became CTO of a Virginia-based company, Flexitral, with Jacquelin Sue Grant as CEO. Flexitral synthesizes odorants based on an algorithm developed from Turin's frequency theory and then markets them to major fragrance companies. Insofar as this project is successful—and it has already had some success in synthesizing more than nine molecules, according to Turin-it will encourage interest in Turin's theory for commercial reasons (as well as scientific reasons).

What is striking about this analysis is that, prior to Chandler Burr's biography, the nonempirical decision vectors were extremely skewed-3 against the frequency theory and none for it. According to Social Empiricism, non-empirical decision vectors should be better balanced. Even with the addition of Chandler Burr's biography, there is still imbalance of 3 to I. Against this background, Luca Turin's move to create a company is quite brilliant, and perhaps more effective than, e.g., more modest moves of presenting 
submitted posters and then papers at conferences. 3:2 is not a bad balance of nonempirical decision vectors.

What if we were to make normative recommendations for improving still further the balance of non-empirical decision vectors? 3:3 would be ideal. Several possible nonempirical decision vectors could do this. One might be the visible support of a prominent scientist. If Turin could persuade a scientist with authority that his theory has merit, then other scientists might, out of respect for that authority, take it more seriously. Or if Turin did the rounds of conferences, presenting as often as he can and networking as much as he can, the cognitive salience of his presence could lead scientists to take his work more seriously. Another possible non-empirical decision vector might be a sequel to Chandler Burr's book, perhaps wide distribution of the BBC video featuring Turin's theory, "A Code in the Nose"-again, something that would draw reasonably positive attention to Turin's theory. The BBC does not make this documentary accessible. And another idea is that, if somehow the biology of smell became a more popular field, more scientists would enter it without preconceived ideas, thus they would be more open to taking frequency theory seriously. Finally, Luca Turin's own book The Secret of Scent has just been published in the UK, and will be published in the USA in the fall of 2006 . The book is written as a science text accessible to the layperson, and it is possible that it will communicate his ideas better than scientific publication. It's possible, on the other hand, that it will be entirely ignored by the scientific community, and that laypersons will not press scientists to take it seriously.

Perhaps my analysis of non-empirical decision vectors is incomplete. A further, more subtle, kind of non-empirical decision vector is ideological factors in the content of the competing theories. So far I have not paid attention to such factors. These are the kind of factors that some feminist critics have detected in particular scientific debates and were outlined above. Is there anything hierarchical, for example, in either the shape or the frequency theory? Or are other gendered assumptions projected onto nature? Starting with the shape theory-and I speculate here-this is reminiscent of one of the cases in the 1988 paper "The Importance of Feminist Critique for Contemporary Cell Biology," written by Scott Gilbert and a group of Swarthmore undergraduates. The authors write of "fertilization metaphors" in organic chemistry. The idea is that the chemical story involves one active and one passive partner. Perhaps in the shape theory the receptor site is like the "passive" egg and the odorant (small, mobile) is like the sperm. The case of the shape theory of smell is, however, unlike the organic chemistry discussed in the Gilbert paper in that, for the shape theory, new molecules do not come of the collision and also there is no language of "attacking" of the larger molecule by the smaller one. But perhaps we can conclude that there is some sexist gender ideology in the shape theory.

Now let's turn to the frequency theory and see if we can detect ideology of gender in that. The language of electron tunneling is one of penetration and probing and shooting (of electrons), which is regularly analyzed as a metaphor of sex from the male point of view. So the frequency theory is also imbued with sexist gender ideology.

If you accept this analysis, a similar ideology underlies both the shape and the frequency theory. So ideology is not contributing to an imbalance of decision vectors (we could add the ideology as a factor in supporting both sides of the debate). ${ }^{9}$ Perhaps it 
would be interesting to explore theories of smell that have non-sexist ideological analysis: but these are not yet developed enough to be part of the discussion. ${ }^{10}$

Note that the presence of sexist ideology is not in itself a criticism of a theory (at least, not according to Social Empiricism). Ideology in science is science as usual. Ideological analysis is just another tool—and a fairly nuanced tool—for looking at and correcting the balance of non-empirical decision vectors.

I conclude that, insofar as gender ideology influences the content of smell theories, it has a similar influence on both the shape and the frequency theories. Without such gender ideology, or with other ideology, other smell theories might be developed. Whether they would be significantly different from the current theories-making different predictions, for example-is not possible to tell in advance.

Gender also plays a role at a different level in this case. Smell is a somewhat neglected branch of neurophysiology, compared with, say, vision or even hearing. Turin speculates that one of the reasons for this is that knowledge about smell is of limited application, particularly of limited medical application. ${ }^{\text {II }}$ And he also offers another reason for the relative neglect of smell by researchers: thinking about smell is regarded as somewhat effete. Turin says:

... there is a definite 'real men don't do this' side to smell and fragrance. I have found that male scientists frequently blush and titter like schoolchildren when given smelling strips during a lecture, whereas women eagerly smell the strips and compare notes with each other. (Turin 2006, p. 6)

If Turin is right about this, there are fewer scientists working on smell than perhaps there should be (by epistemic fairness considerations). Moreover, those scientists who do work on smell—predominantly male, as are all scientists—are typically fairly ignorant of (and uninterested in) odor and fragrance.

This gender bias does not favor either the shape or the frequency theory. It influences general interest in the field of smell, interest in exploring data about odors and salience of data about odors. Should such gender bias be corrected, and if so, with what kinds of diversity? This question is not answered by the framework of Social Empiricism, which addresses the distribution of cognitive labor over alternative theories. Here is where we need a discussion of the distribution of cognitive labor over different scientific fields. I plan to have that discussion in future work.

Turin is in the rare position of having both scientific credentials and a great nose. Unlike most smell scientists, he is in a good position to discover that the shape theory doesn't do much predictive or explanatory work. He is in a good position to develop and test an alternative theory. The precise character of that theory-that smell is detected by inelastic electron tunneling-is not suggested by Turin's special talents and interests. Perhaps here, Turin's general physics background was helpful. It should also be noted that Turin is an outsider to the smell community-his prior scientific work was on unrelated topics-and that creative contributions to a field are often made by outsiders who have the interdisciplinary knowledge to make a breakthrough.

Creativity is not a mysterious process of intuition, magic or divine inspiration. Cognitive scientists (e.g., Boden 1990) have both characterized creativity and specified 
some strategies, talents, and techniques that contribute to creativity. Examples of these are associative thinking with a well-stocked associative memory (understood on a connectionist model), analogical inference (again understood in terms of neural nets), willingness to experiment by dropping standard constraints (often more common in the young or in those outside professional institutions), as well as chance, chaos, randomness, and unpredictability, always bearing in mind that, as Louis Pasteur said, "fortune favors the prepared mind." The development of Turin's smell theory can be understood in these terms. His background as a biophysicist knowledgeable about perfume (and not threatened by the image of the effete perfumer), and his habit of reading widely in historical as well as contemporary scientific texts put him in a unique positiondifferent from establishment smell researchers - to notice what is wrong with the shape theory and to build a new theory, based in part on his prior research on conductivity of proteins. While Turin offers unique cognitive diversity to the smell debate, he is not the only person who could ever have put forward another smell theory or even a frequency smell theory. One can imagine, at least in broad outline, other routes to a similar or the same end. For example, a biophysicist/geneticist with a focus on the mechanism of smell detectors could have led to the discovery of the importance of vibrational frequency, and the discovery of different shaped molecules smelling the same made later on. Again, diversity is a somewhat blunt epistemic tool.

The framework of Social Empiricism-as most social epistemologies-addresses division of epistemic labor in a field where the alternatives are already specified. It does not address overall attention to a field, or development of the alternatives. While I have paid attention to these questions here, and said something about Turin's creativity, I have not said anything general about epistemic diversity and scientific attention to a field, or epistemic diversity and creativity. The most I can say now is, "yes, diversity is a good thing," but that does not specify the amount or the type of diversity, even relative to a particular field. And although I suggested that gender ideology might be playing a role both in influencing the kinds of available theories about smell and in reducing the amount of overall attention given to scientific work, other ideological analyses (in terms of political constructs other than gender) or explorations of human cognitive strategies may suggest further kinds of epistemically relevant diversity.

\section{CONCLUSIONS}

Appropriate norms of epistemic diversity are neither laissez-faire nor specific recommendations to increase or decrease particular types of diversity. According to Social Empiricism, the epistemic goal is to better balance the decision vectors, and there are a number of ways of going about this in any particular case, all of which typically increase epistemic diversity. Also, various kinds of cognitive diversity were found to be important both for increasing general attention to a field and for creating new theories and strategies. The normative recommendations for general attention to a field and for creativity are so far unspecified, although diversity clearly plays an important role. Diversity is regarded as a blunt epistemic tool, with more than one route to balancing the decision vectors, improving the social distribution of research effort and knowledge, and creating new theories. 


\section{ACKNOWLEDGEMENTS}

This paper was presented at the Episteme conference on 2 June 2006. I am grateful to the audience for their helpful comments, and also to James Robert Brown, Alvin Goldman and Alison Wylie for their suggestions for revision of the paper.

\section{REFERENCES}

Barad, Karen (1998) "Agential Realism: Feminist Interventions in Understanding Scientific Practices," in Mario Biagioli, ed., The Science Studies Reader. New York: Routledge.

Beldecos, Athena et. al (1988) "The Importance of Feminist Critique for Contemporary Cell Biology," Hypatia 3:1 Reprinted in Nancy Tuana, ed., Feminism and Science (1989). Bloomington, IN: Indiana University Press.

The Biology and Gender Study Group (1988) "The Importance of Feminist Critique for Contemporary Cell Biology." Reprinted in Nancy Tuana, ed. Feminism and Science (1989), pp. 172-187. Bloomington, IN: Indiana University Press.

Boden, Margaret (1990) The Creative Mind: Myths and Mechanisms. New York: Basic Books.

Burr, Chandler (2002) The Emperor of Scent: A Story of Perfume, Obsession and the Last Mystery of the Senses. New York: Random House.

Dyson, G. M. (1938) “The Scientific Basis of Odour," Chemistry and Industry 57: 647-65I.

Goldman, Alvin and Moshe Shaked (1992) "An Economic Model of Scientific Activity and Truth Acquisition." In Alvin Goldman, Liaisons: Philosophy Meets the Cognitive and Social Sciences. Cambridge, MA: MIT Press.

Grinnell, Frederick (1992) The Scientific Attitude, 2nd edition. New York: Guilford Press.

Keller, Andreas and Leslie Vosshall (2004) "A Psychophysical Test of the Vibration Theory of Olefaction," Nature Neuroscience, March 21, 2004. Published online at http://www.nature. com/natureneuroscience/

Keller, Evelyn Fox (1979) “Cognitive Repression in Contemporary Physics”. American Journal of Physics 47(8): 718-21. Reprinted in Evelyn Fox Keller (1985).

- (1985) Reflections on Gender and Science. New Haven: Yale University Press.

Kitcher, Philip (1993) The Advancement of Science. New York: Oxford University Press.

Longino, Helen (1990) Science as Social Knowledge: Values and Objectivity in Scientific Inquiry. Princeton, NJ: Princeton University Press

Polanyi, Michael (1962) “The Republic of Science: Its Political and Economic Theory”, in Marjorie Grene, ed., Knowing and Being: Essays by Michael Polanyi. Chicago: University of Chicago Press, 1969.

Solomon, Miriam (2001) Social Empiricism. Cambridge, MA: MIT Press.

Sunstein, Cass $(2003)$ Why Societies Need Dissent. Cambridge, MA: Harvard University Press.

Suroweicki, James (2004) The Wisdom of Crowds. New York: Doubleday

Turin, Luca (1992) Parfums: Le Guide (Herme, Paris). A 1994 version is available online (www. flexitral.com/research.html)

- (2004) "Rational Odorant Design," in David Rowe ed. Chemistry and Technology of Flavours and Fragrances. Blackwells.

— Website on Flexitral. Last accessed March 29, 2006. http://www.flexitral.com

- (2006) The Secret of Scent: Adventures in Perfume and the Science of Smell. London: Faber and Faber.

— (2006) "Accords and Discords: Perfume Reviews," in J. Drobnick, ed., The Smell Culture Reader. Oxford: Berg. 
Turin, Luca and Fumiko Yoshii (2003) "Structure-Odor Relations: A Modern Perspective," in Richard Doty, ed., Handbook of Olfaction and Gustation, 2nd edition. Marcel Decker.

Wright, R.H. (1977) “Odor and Molecular Vibration: Neural Coding of Olfactory Information,” Journal of Theoretical Biology 64(3): 473-502.

\section{NOTES}

I It is hard to identify someone who espouses this position, at least in an unqualified way. Probably Feyerabend is an example. Grinnell and Kitcher, examples mentioned later in the text, probably only partially espouse this position.

2 Sunstein does not value dissent because of the criticism it produces; dissent is valued primarily because it is a sign of possible differences in information.

3 It is, emphatically, not a blunt political tool. In political contexts representation of all points of view, in their specificity, is typically necessary.

4 What counts as "empirical success" is explored in Chapter 2 of (200I).

5 This is not the place to justify this normative account. For those who have not read Social Empiricism, I acknowledge there that the "decision vectors" account is somewhat crude, since it does not include strength of each decision vector. (It treats all decision vectors as equal in strength.) Technically, it is an improper linear model. Proper linear models certainly do better, but the surprise is that improper linear models do quite well, and certainly better than qualitative assessments. In the absence of data for a proper linear model, I do the best I can.

6 Social Empiricism has many more examples, but it is time for something fresh.

7 I am grateful to Alison Wylie for sending me a copy of this book and suggesting that I analyze it in terms of the normative concepts from Social Empiricism.

8 Of course, being good empiricists, we would like to see a new prediction made using this modified theory, in order to test it. (None yet.)

9 Here's another attempt at an ideological analysis of smell theories. It is less convincing than the one in the main text, so I relegate it to a footnote. Shape theory is a mechanistic theory. It is almost Cartesian in its description of secondary properties (smell) and the causative primary qualities (shape of molecules). Frequency theory, on the other hand, is based on a quantum mechanical theory about electron tunneling, in which electrons have a wave function and move through proteins in probabilistic ways. What is the ideology here? Perhaps Evelyn Fox Keller's (1979) analysis of ideology in quantum mechanics can help. Keller argues that quantum mechanics should be understood as requiring an "interaction between knower and known." But nothing that Turin says suggests that he is using these quantum aspects of his own theory. Indeed, shape theory is also quantum mechanical, in that the shapes of molecules are predicted by quantum mechanics. And also, subjective versus objective interpretations of quantum mechanics are not the issue here.

Io They would need to be developed enough to have associated empirical success that the other theories do not have. They haven't even been stated yet.

II I have some doubts about this explanation; lots of research on vision has no apparent medical applications.

Miriam Solomon is Professor of Philosophy at Temple University. Her research interests are in philosophy of science, philosophy of medicine, epistemology and feminist philosophy. She is the author of Social Empiricism (MIT Press, 200I) and numerous articles in journals and anthologies. 